\title{
NUTRItion and CLIMate (NUTRICLIM): investigating the relationship between climate variables and childhood malnutrition through agriculture, an exploratory study in Burkina Faso
}

\author{
Raissa Sorgho ${ }^{1 *}$, Jonas Franke ${ }^{2}$, Seraphin Simboro ${ }^{3}$, Revati Phalkey ${ }^{4}$ and Rainer Saeurborn ${ }^{1}$
}

\author{
* Correspondence: \\ raissa.sorgho@uni-heidelberg.de \\ ${ }^{1}$ Institute of Public Health, \\ Universitats Klinikum, Heidelberg, \\ Germany \\ Full list of author information is \\ available at the end of the article
}

\begin{abstract}
Malnutrition remains a leading cause of death in children in low- and middle-income countries; this will be aggravated by climate change. Annually, 6.9 million deaths of children under 5 were attributable directly or indirectly to malnutrition. Although these figures have recently decreased, evidence shows that a world with a medium climate (local warming up to $3-4{ }^{\circ} \mathrm{C}$ ) will create an additional 25.2 million malnourished children. This proof of concept study explores the relationships between childhood malnutrition (more specifically stunting), regional agricultural yields, and climate variables through the use of remote sensing (RS) satellite imaging along with algorithms to predict the effect of climate variability on agricultural yields and on malnutrition of children under 5. The success of this proof of purpose study, NUTRItion and CLIMate (NUTRICLIM), should encourage researchers to apply both concept and tools to study of the link between weather variability, crop yield, and malnutrition on a larger scale. It would also allow for linking such micro-level data to climate models and address the challenge of projecting the additional impact of childhood malnutrition from climate change to various policy relevant time horizons.
\end{abstract}

Keywords: Malnutrition, Low- and middle-income countries, Climate change, Stunting, Remote sensing, Weather

\section{Main text}

Malnutrition is globally recognized as having one of the largest adverse effects on the growth of nations, because it not only poses a challenge to the health but also to the productivity of populations [1]. Unfortunately, climate change will have an additional negative impact on childhood nutrition through a large number of factors [1,2]. While malnutrition in children has globally decreased over the past few decades, climate change has the potential to reverse the recent gains in the global reduction of malnutrition [3]. A median climate (local warming up to $3-4{ }^{\circ} \mathrm{C}$ ) is projected to create an additional 25.2 million malnourished children [2, 4]. The 2015 Rockefeller Foundation and Lancet Commission on Planetary Health publication titled: Safeguarding human health in the Anthropocene epoch, states along with the IPCC that "... median crop 
yields would decrease by $0-2 \%$ per decade for the remainder of the century, as a result of climate change alone, with or without adaptation, whereas demands for crops are projected to increase by $14 \%$ per decade up to 2050 " [5, 6]. The publication continues by detailing that the projected decreases in crop yields result in increasing numbers of stunted children, especially in Asia and Africa. More than $90 \%$ of the world's stunted children live in Africa and Asia [7]. Currently, $36 \%$ of all children under 5 years in sub-Saharan Africa suffer from stunting-a severe form of malnutrition [1, 2]. Projections forecast that stunting will increase by approximately $23 \%$ in the region; this is why we selected a sub-Saharan African country as the site of this proof of concept exploratory study [2].

The relationship between changing climate, agriculture, and malnutrition is influenced by a multitude of factors. The complexity and interdisciplinary nature of these three issues converge into an elaborate web, which is represented in Fig. 1. The convolution of these links is precisely the reason these connections have been understudied.

Figure 1 illustrates an aspect of the complexity of the relationships investigated. Each of the three colored boxes represents one of three pillars: climate, agriculture, and malnutrition. Each arrow represents a relationship between two variables or factors. The three pillars converge on the subject of food crops and food yields.

This exploratory study, NUTRItion and CLIMate (NUTRICLIM), in Burkina Faso aims to investigate the relationship between weather variability, crop yields, household socioeconomic variables, and malnutrition. The study village of Bourasso, which has 12,548 inhabitants, in the rural Kossi Province is located $25 \mathrm{~km}$ from the small town of Nouna. The study involves 156 individuals, subdivided into 20 households with 29 children under the age of 5 . This first sample was randomly selected from the INDEPTH Human Demographic Surveillance System (HDSS) database of the Centre de Recherché en Santé de Nouna (CRSN) and the second sample from local Bourasso Health Post's database of malnourished children [8]. The 20 households can thus be subdivided into sample 1: 10 households that were randomly selected and coincidentally had no malnourished children under the age of 5, and sample 2: 10 households that were purposefully selected for having children under the age of 5 who were undergoing treatment

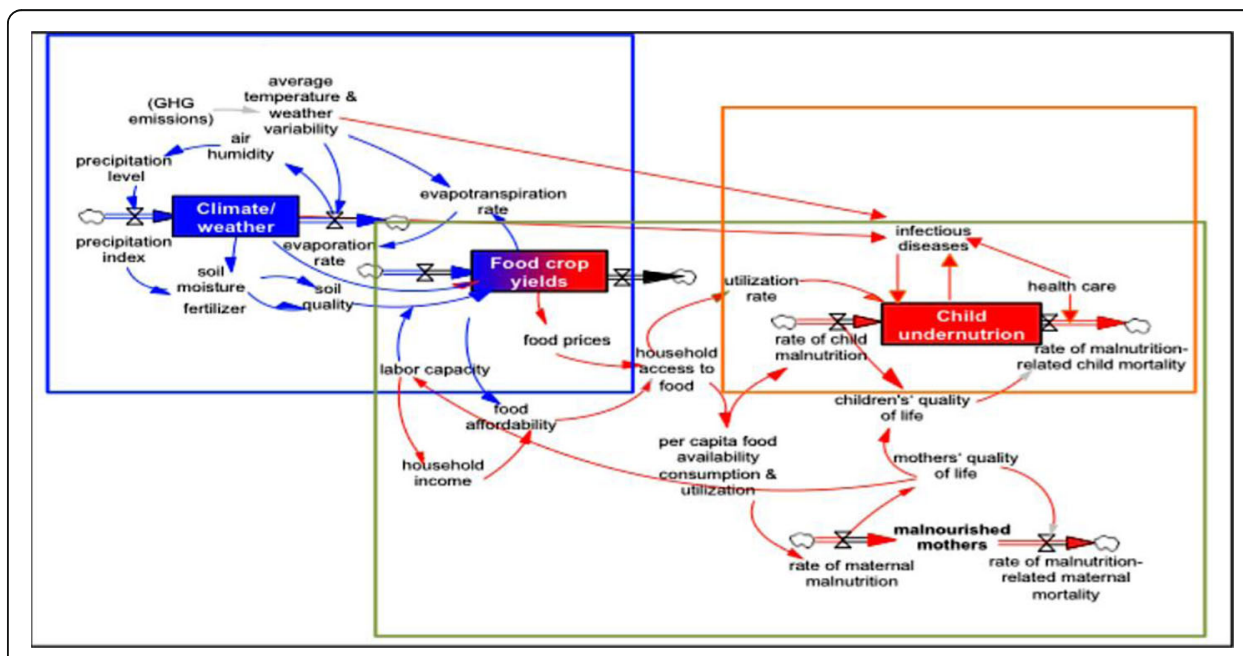

Fig. 1 The complexity and interdisciplinary nature of these three issues converge into an elaborate web. Adapted from Phalkey et al. [1] 
for malnutrition. The additional selection criteria were that all 20 households be subsistence farmers, living in the village of Bourasso, with at least one child under the age of 5 .

Data for the first pillar, climate, were acquired through the two nearest local weather stations of the HDSS. The weather stations provide information on median daily temperature, daily rainfall, as well as seasonal distribution and variability of rainfall.

Data for the second pillar, agriculture, was collected through two methods. The first method was harvest yields reported by farmers and converted from local measures into kilograms. The second was innovative in that it estimated plot level yields by household and crop using special algorithms from remotely sensed data of the village and its surroundings. This required the delineation of each field of all households with the farmers using a GPS to establish the polygons. These were overlaid with scenes from the RapidEye satellite, covering the agricultural fields of the 20 selected households. We carried out ground validation through verification and comparison of the results from remote sensing (RS) satellite imaging; field agents physically verified that the satellite readings matched ground data. Postharvest, the figures of the actual agricultural yields are used as input data to better calibrate the algorithms for modeling crop yields on a micro-level (household level).

The third pillar covered malnutrition and health. This data was collected using a socioeconomic and morbidity questionnaire for the selected households. The survey assessed (i) household assets, revenues, and expenditure, (ii) a 24-hour nutritional recall journal of all children under 5, and (iii) all recent child illnesses within the household, both chronic and acute (episodes of diarrhea, malaria, etc.). Furthermore, we used standard anthropometry (weight, height, and mid-upper-arm circumference) to assess the nutritional status of children under the age of 5 .

As data analysis was still in progress at the time of the presentation at the COP21, no definitive results could be stated. But preliminary findings indicate the possibility of disparities in the agricultural yield of households with and without malnourished children and between years with average and low rainfall. The differences were noticed not only in the types of crops sown but also in the number of plots owned by the households: households with healthy children had, on average, a greater number of fields. When the subsistence farmers were questioned on their yields, only one third classified their harvest as good, allowing the household to be fed in a satisfactory manner for the entire year until the next harvest. The remaining two thirds of all households attributed insufficient yields to bad rains, changing rain patterns, or unpredictable rain patterns. This potentially highlights the significance of changing weather patterns and their consequences in terms of droughts $[4,9]$.

\section{Conclusions}

We laid out a number of field methods in the fields of meteorology, agriculture, nutrition, and health that allow for the study of the web of causation of childhood malnutrition with a particular focus on the role of weather and climate in the future.

We propose that large-scale studies using these methods, amongst others, be considered. These could then be linked to downscaled climate models in cooperation with climate scientists in order to establish data-based projections of the future impact of climate change on malnutrition rather than relying on a set of assumptions and mono-disciplinary fragmented studies. 
Abbreviations

CRSNm: Centre de Recherche en Sante de Nouna; HDSS: Human Demographic Surveillance System

\section{Acknowledgements}

We would like to thank the people of Bourasso for the time they accorded to the collection of this pilot study data.

\section{Funding}

Pilot study was funded by the institute of Public Health at the University of Heidelberg.

\section{Availability of data and materials}

The datasets generated during the current study are not publicly available due to the fact that they are still being analyzed and are to be utilized for further publication before public release. But this data can be made available from the corresponding author on reasonable request.

\section{Authors' contributions}

RSorgho is the field research coordinator, author and COP21 presenter. JF is the Remote Sensing and Rapid Eye Imaging expert. SS is the cartography and GIS expert. RP is the study co-supervisor. RSauerborn is the editor, reviwer and study supervisor. All authors read and approved the final manuscript.

\section{Authors' information}

Raissa Sorgho is a researcher on two climate and health studies at the Institute of Public Health in Heidelberg, Germany. Her background is in biology, and she is currently a candidate for a Master of Science in International Health while simultaneously working on her doctorate. Her research interests include agriculture, nutrition, health financing, and climate change.

\section{Competing interests}

The authors declare that they have no competing interests.

\section{Consent for publication}

Not applicable.

\section{Ethics approval and consent to participate}

The study NUTRICLIM was approved by the Heidelberg University ethical committee "Ethik Kommission Medizinische Fakultät Heidelberg". Furthermore, in observation of ethically appropriate scientific research, NUTRICLIM followed the procedures of the ongoing Nouna Socioeconomic and Health Panel Survey (SOHPS). This is the process, which has been utilized by the CRSN research center since 2000. For the anthropometric component of the study, NUTRICLIM followed standard WHO procedures. The study team ensured that all malnutrition cases discovered during the course of the study would be presented to the CSPS and, if needed, be referred to Centre de Rehabilitation Nutritional (CREN) in the district capital Nouna. The project contributed $50 \%$ of all rehabilitation and care cost for such children. Lastly, the project had no environment impact.

All participants consented verbally and in written form to partake in the study. Participation in the research study was entirely voluntary; it had and will continue to have no effects or repercussions on the work or social life of participants. Participants were free to change their minds at any point, ceasing participation at will. There were no costs associated with participation nor were there financial incentives. The information collected in the framework of this research project was confidential. This information was stored in a file number anonymously. All consequent files were replaced with a unique identification number. No information was shared with anybody outside the research team. The knowledge gained from this research will be published so that other interested persons may learn from the research.

\section{Author details}

${ }^{1}$ Institute of Public Health, Universitats Klinikum, Heidelberg, Germany. ${ }^{2}$ Remote Sensing Solution GmBh (RSS), Environmental Consulting, Baierbrunn, Germany. ${ }^{3}$ Centre de Recherche en Santé de Nouna (CRSN), Research Center, INDEPTH Network, HDSS, Nouna, Burkina Faso. 'Division of Epidemiology and Public Health, University of Nottingham, Nottingham, UK.

\section{Received: 15 September 2016 Accepted: 22 September 2016}

Published online: 06 October 2016

\section{References}

1. Phalkey R, Aranda-Jan C, Marx S, Höfle B, Sauerborn R. A systematic review of current efforts to quantify the impacts of climate change on undernutrition. PNAS. 2015;112(33):E4522-9. doi:10.1073/pnas.1409769112.

2. Lloyd SJ, et al. Climate change, crop yields, and undernutrition: development of a model to quantify the impact of climate scenarios on child undernutrition. Environ Health Perspect. 2011;119(12):1817-23.

3. Woodward A, Smith K, Campbell-Lendrum D, Chadee D, Honda Y, Liu Q, Olwoch J, Revich B, Sauerborn R, Chafe Z, Haines A. Climate change and health—the latest report from the IPCC. Lancet. 2014;283:1185-9.

4. Whitmee S, Haines A, Beyrer C, Boltz F, Capon AG, de Souza Dias BF, et al. Safeguarding human health in the Anthropocene epoch: report of The Rockefeller Foundation-Lancet Commission on planetary health (Haines A Chair of Commission). Lancet. 2015:386:1973-2028.

5. Lobell DB, et al. Prioritizing climate change adaptation needs for food security in 2030. Science. 2008;319(5863):607-10. 
6. Nelson GC, Rosegrant MW, Koo J, Robertson R, Sulser T, Zhu T, et al. Climate change: impact on agriculture and costs of adaptation. food policy report. Washington, DC: International Food Policy Research Institute; 2009. p. 1-30.

7. UNICEF. UNICEF-WHO-World Bank Joint Child Malnutrition Estimates. 2012. Available at www.who.int/nutgrowthdb/ jme_unicef_who_wb.pdf. Accessed January 10, 2015.

8. Sankoh O, Byass P. The INDEPTH Network: filling vital gaps in global epidemiology. Intl J Epidem. 2012;41:579-88.

9. Anyamba A, Chretien JP, Small J, Tucker CJ, Linthicum KJ. Developing global climate anomalies suggest potential disease risks for 2006-2007. Int J Health Geogr. 2006;28:5. 60.

Submit your next manuscript to BioMed Central and we will help you at every step:

- We accept pre-submission inquiries

- Our selector tool helps you to find the most relevant journal

- We provide round the clock customer support

- Convenient online submission

- Thorough peer review

- Inclusion in PubMed and all major indexing services

- Maximum visibility for your research

Submit your manuscript at www.biomedcentral.com/submit 